\title{
Phytochemical Profiles and Antioxidant and Antimicrobial Activities of the Leaves of Zanthoxylum bungeanum
}

\author{
Yujuan Zhang, Ziwen Luo, Dongmei Wang, Fengyuan He, and Dengwu Li \\ College of Forestry, Northwest A\&F University, Yangling 712100, China \\ Correspondence should be addressed to Dongmei Wang; dmwli@163.com
}

Received 5 May 2014; Revised 3 July 2014; Accepted 8 July 2014; Published 24 July 2014

Academic Editor: Wanchai De-Eknamkul

Copyright (C) 2014 Yujuan Zhang et al. This is an open access article distributed under the Creative Commons Attribution License, which permits unrestricted use, distribution, and reproduction in any medium, provided the original work is properly cited.

\begin{abstract}
The ethanol crude extracts (ECE) and their subfractions from Zanthoxylum bungeanum leaves were prepared and their phytochemical profiles and antioxidant and antimicrobial activities were investigated. Moreover, the effective HPLC procedure for simultaneous quantification of twelve compounds in $Z$. bungeanum leaves was established. The correlation between the phytochemicals and antioxidant activity was also discussed. The ethyl acetate fraction (EAF) had the highest total phenolic (97.29 mmol GAE/100 g) and flavonoid content $(67.93 \mathrm{mmol}$ QE/100 g), while the greatest total alkaloid content $(4.39 \mathrm{mmol} \mathrm{GAE} / 100 \mathrm{~g})$ was observed in the chloroform fraction (CF). Twelve compounds were quantified by RP-HPLC assay. EAF exhibited the highest content of quercitrin, kaempferol-3-rhamnoside, quercetin, sesamin, and nitidine chloride $(125.21,54.95,24.36,26.24$, and $0.20 \mathrm{mg} / \mathrm{g})$; acetone fraction (AF) contained the highest content of chlorogenic acid, rutin, hyperoside, and trifolin (5.87, 29.94, 98.33, and 31.24 mg/g), while kaempferol-3-rhamnoside, xanthyletin, and sesamin were rich in CF. EAF and AF exhibited significant DPPH, ABTS radical scavenging abilities and reducing power (FRAP), whereas CF exhibited significant antifungal activity. Moreover, EAF also showed stronger antibacterial activity. In conclusion, Z. bungeanum leaves have health benefits when consumed and could be served as an accessible source for production of functional food ingredients and medicinal exploration.
\end{abstract}

\section{Introduction}

Zanthoxylum bungeanum, known as the Da Hongpao Huajiao, which belongs to the Zanthoxylum genus of the family Rutaceae, is widely distributed in Hebei, Shanxi, Sichuan, Gansu, and Shandong provinces of China and some Southern Asian countries [1]. Just like other species of this genus, $Z$. bungeanum has a distinctive tingling taste. Due to its fresh aroma and taste, the dried fruits are used ground or whole as a spice in local cuisines, which can stimulate saliva production and increase appetite [2]. Consisting of salt and Sichuan pepper (Z. bungeanum), hua jiao yen is often used as a condiment in barbecue foods, such as chicken tikka or roast duck. Apart from its common application as a condiment to make foods more flavoring, each part of $Z$. bungeanum has numerous medicinal virtues. In traditional Chinese medicine, the pericarp can be used for gastralgia and dyspepsia; the seed is reported to be antiphlogistic and diuretic; the leaves are considered carminative, stimulant, and sudorific; the root can cure epigastric pains and treat bruises, eczema, and snakebites [3-7]. Recent experimental studies have shown that the pericarp of $Z$. bungeanum possesses cardiovascular activity [8]; it also can be used as an ingredient in cosmetic products [9]; methanol extracts of $Z$. bungeanum have anti-inflammatory activity [10]; the essential oil of seed and fruit exhibits marked antioxidant activity as well as antimicrobial activity [11-13].

The leaves of $Z$. bungeanum are edible; they taste acrid and innocuous. In some rural areas, local people eat the new leaves as vegetables in spring seasons [14]. Furthermore, it is also commonly used as condiments in Chinese cuisine and in the preparation of refreshments to add flavor [11]. In spite of its long history of consumption, only a few people pay attention to the chemical work on this material. Fan and coworkers did a study on the ultrasonic-assisted extraction of total flavonoids from $Z$. bungeanum leaves [15]. Yang and coworkers identified 13 polyphenolics from the leaves of $Z$. bungeanum grown in Hebei, China, by HPLC/MS, among which chlorogenic acid, hyperoside, and quercitrin were the major constituents [1]. But, there are still some unclear points 
for consumers on the phytochemical profiles and physiological effects of this edible material. In order to fully investigate, utilize, and develop this material, we designed an experiment: (1) to evaluate the contents of total flavonoid, phenol, and alkaloid in the different polarity fractions of $Z$. bungeanum leaves; (2) to measure the antioxidant and antimicrobial activities of the different polarity fractions; (3) to quantify the content of twelve natural compounds (chlorogenic acid, epicatechin, rutin, hyperoside, trifolin, quercitrin, kaempferol3-rhamnoside, quercetin, nitidine chloride, chelerythrine, xanthyletin, and sesamin) in the different polarity fractions by RP-HPLC analysis; and (4) to compare the similarities and differences of the phytochemical composition in the different polarity fractions. Based on these results, the most bioactive fraction could be selected as a potential source of natural antioxidants and antiseptics. In addition, phytochemicals might be responsible for their profound bioproperties which will be screened out. The results also could explain its frequent addition to the Chinese diet for promoting human health and for disease prevention.

\section{Materials and Methods}

2.1. Plant Material and Chemicals. Z. bungeanum leaves were collected from Taibai Mountains of Shaanxi province, China, in September, 2012, and authenticated by the Herbarium of the Northwest A\&F University, Yangling, China.

The following were obtained: Folin-Ciocalteu reagent (Shanghai Solarbio Bioscience \& Technology Co., Ltd., China); 1,1-diphenyl-2-picrylhydrazyl (DPPH), 2,2-azinobis(3-ethylbenzothiazoline-6-sulphonic acid) diammonium salt (ABTS), 2,4,6-tripyridyl-s-triazine (TPTZ), and 6hydroxy-2,5,7,8-tetramethylchroman-2-carboxylic acid (Trolox) (Sigma-Aldrich Co., St. Louis, USA); vanillin, bromocresol green, tetrahydrofuran (THF), sodium borohydride, and trifluoroacetic acid (Chengdu Kelong Chemical Co., Ltd., China); chloranil (Aladdin Industrial Corporation, Shanghai, China); gallic acid, chlorogenic acid, epicatechin, rutin, hyperoside, trifolin, quercitrin, kaempferol-3-rhamnoside, quercetin, nitidine chloride, chelerythrine, xanthyletin, and sesamin (Shanghai Winherb Medical Science Co., Ltd.); and amphotericin and benzylpenicillin (Shanghai Sunny Biotechnology Co. Ltd., China). All solvents used were of AR-grade. Deionized water $(18 \mathrm{M} \Omega \mathrm{cm})$ was used to prepare aqueous solutions.

Twenty fungi (Botrytis cinerea, Piricularia oryzae, Physalospora piricola, Glomerella cingulata, and Venturia pyrina, etc.) and two Gram-positive (Staphylococcus aureus and Bacillus subtilis) and one Gram-negative (Escherichia coli) bacteria were provided by the College of Resources and Environment, Northwest A\&F University, China.

\subsection{Preparation of the Ethanol Crude Extracts and Fractions.} The air-dried and powdered leaves of Z. bungeanum $(9.40 \mathrm{Kg})$ were extracted using 95\% ethanol at room temperature for $24 \mathrm{~h}$, with solid to liquid ratio of $1: 5$, repeating 6 times. The ethanol crude extracts (ECE, $1839.96 \mathrm{~g}$ ) were filtered and evaporated to dryness by rotary evaporation at $45^{\circ} \mathrm{C}$ under reduced pressure. $15.56 \mathrm{~g}$ of ECE was stored for further analysis. The remaining ECE (1824.40 g) was further fractioned by column chromatography on silica gel (silica gel 200$300 \mathrm{mesh}, 120 * 10 \mathrm{~cm}$ i.d., flow rate $10 \mathrm{~mL} / \mathrm{min}$ ), successively eluting with petroleum ether, chloroform, ethyl acetate, acetone, and methanol. The eluents of the five different polarity solvents were collected separately and evaporated to dryness by rotary evaporation at $45^{\circ} \mathrm{C}$ under reduced pressure. Thus, the different polarity fractions (PEF, $105.98 \mathrm{~g}$; CF, $112.76 \mathrm{~g}$; EAF, $40.70 \mathrm{~g}$; AF, $124.93 \mathrm{~g}$; and MF, $624.35 \mathrm{~g}$ ) were obtained and carefully stored at $-20^{\circ} \mathrm{C}$ and protected from light until further analysis $[16,17]$.

\subsection{Determination of Total Flavonoid Content (SBC Method).} The total flavonoid content (TFC) was determined based on a SBC assay using sodium borohydride/chloranil as described previously [18-20]. This assay allows the detection of numerous flavonoid varieties, including flavones, flavonols, flavonones, flavononols, isoflavonoids, and anthocyanins [20]. A calibration curve was constructed to create a standard using different concentrations of quercetin (0.1$10.0 \mathrm{mM})$. TFC of extracts and different polarity fractions from $Z$. bungeanum leaves were expressed as mmol quercetin equivalent per $100 \mathrm{~g}$ and all samples were evaluated in triplicate.

2.4. Determination of Total Phenolic Content. The total phenolic content (TPC) was determined using the FolinCiocalteu colorimetric method as described previously [21, 22]. TPC was calculated by gallic acid equivalent from the calibration curve from the gallic acid standard solutions (20$300 \mu \mathrm{g} / \mathrm{mL}$ ). TPC of extracts and different polarity fractions from $Z$. bungeanum leaves were expressed as mmol gallic acid equivalent per $100 \mathrm{~g}$, and all the samples were measured in triplicate.

2.5. Determination of Total Alkaloid Content. The total alkaloid content (TAC) was determined using the acid dye colorimetric method with the following modifications [23]. Chelerythrine $(0.2-1.0 \mathrm{mg} / \mathrm{mL})$ was used as a reference for the calibration curve. TAC of extracts and different polarity fractions from $Z$. bungeanum leaves were expressed as mmol of chelerythrine equivalent per $100 \mathrm{~g}$, and all of the samples were analyzed in triplicate.

2.6. Assessment of the Twelve Compounds by HPLC. The content of twelve compounds (chlorogenic acid, epicatechin, rutin, hyperoside, trifolin, quercitrin, kaempferol3-rhamnoside, quercetin, nitidine chloride, chelerythrine, xanthyletin, and sesamin) was assayed using an Agilent Technologies 1260 series liquid chromatograph (RP-HPLC) coupled with a variable wavelength detector. The quantification was carried out on a SB-C18 reversed phase column $(5 \mu \mathrm{m}, 4.6 * 250 \mathrm{~mm})$ at ambient temperature $[24,25]$. The mobile phase consisted of water with $0.5 \%$ trifluoroacetic acid (solvent $\mathrm{A}$ ) and acetonitrile with $0.5 \%$ trifluoroacetic acid (solvent B). The flow rate was $0.8 \mathrm{~mL} / \mathrm{min}$. The gradient program was set as follows: from 0 to $30 \mathrm{~min}$, eluent $\mathrm{B}$ was 
increased from $15 \%$ to $35 \%$; from 30 to $35 \mathrm{~min}$, eluent B was increased from $35 \%$ to $65 \%$; and from 35 to $55 \mathrm{~min}$, eluent $\mathrm{B}$ was increased from $65 \%$ to $100 \%$ and then maintained at $100 \%$ for $10-20 \mathrm{~min}$. The injection volume was $20 \mu \mathrm{L}$ and the detection wavelength was $254 \mathrm{~nm}$. Samples were filtered through a $0.22 \mu \mathrm{m}$ membrane filter prior to injection. The major constituents in the ECE and its five different polarity fractions were identified by comparing their retention times and the spectral characteristics of their peaks with those of the standards. The analyses were all performed in triplicate.

2.7. Validation of the HPLC Method. The linear calibration curves contained six different concentrations of each standard compound by a series of appropriate dilutions with mobile phase. All calibration curves were constructed by plotting the peak areas of the standard substances versus the corresponding concentrations of the injected standard solutions.

The HPLC procedure was also validated for its precision, reproducibility, and recovery test [26]. To determine the precision of the procedure, the standard compounds solutions were analyzed in triplicate for three times within one day, while for interday variability, the samples were examined in triplicate for three consecutive days. To determine the reproducibility, six working solutions were prepared using the ethanol crude extractions (ECE, $5 \mathrm{mg} / \mathrm{mL}$ ). The recovery test was used to evaluate the accuracy of the proposed method. Accuracy was determined by adding different concentrations of the mixed standard solutions into the known amounts of sample solutions of ECE. Then the compounds in the resultant samples were analyzed with the proposed method. The recovery was calculated as follows:

$$
\begin{aligned}
& \text { Recovery }(\%) \\
& =\left(\frac{\text { total detected amount }- \text { original amount }}{\text { added amount }}\right) * 100 .
\end{aligned}
$$

The RSD values were taken as measurements for precision, reproducibility, and recovery tests.

2.8. DPPH Radical Scavenging Activity. DPPH radical scavenging activity was evaluated using the method described by Yen and Chen [27] and Sultana et al. [28] with some modifications [17]. A $2 \mathrm{~mL}$ volume of the sample solutions (20$1000 \mu \mathrm{g} / \mathrm{mL}$ ) or the positive controls rutin and quercetin (1$200 \mu \mathrm{g} / \mathrm{mL})$ was added to $2 \mathrm{~mL}$ of DPPH solution $(100 \mu \mathrm{M})$; and the absorbance was measured with a spectrophotometer (Shimadzu UV-1800) at $517 \mathrm{~nm}$ after standing in the dark for $30 \mathrm{~min}$. All the tests and the controls were repeated in triplicate. The DPPH free radical scavenging activity was calculated using the following equation:

$$
\text { Scavenging }(\%)=\left[\frac{1-\left(A_{i}-A_{j}\right)}{A_{o}}\right] \times 100 \% \text {, }
$$

where $A_{o}$ is the absorbance of ethanol $(2 \mathrm{~mL})$ and DPPH. $(2 \mathrm{~mL}), A_{i}$ is the absorbance of the tested sample $(2 \mathrm{~mL}$ sample and $2 \mathrm{~mL} \mathrm{DPPH} \cdot)$, and $A_{j}$ is the absorbance of the blank ( $2 \mathrm{~mL}$ sample and $2 \mathrm{~mL}$ ethanol).

2.9. ABTS Radical Cation Decolorization Assay. Antioxidant activity was determined according to the decolorizing free radical ABTS. ${ }^{+}$method [29] as described previously [3032]. For each analysis, $100 \mu \mathrm{L}$ of sample $(1 \mathrm{mg} / \mathrm{mL})$ and the positive controls (rutin and quercetin, $0.05 \mathrm{mg} / \mathrm{mL}$ ) was added to $3.9 \mathrm{~mL}$ of the ABTS. ${ }^{+}$solution, and the decrease in absorbance at $734 \mathrm{~nm}$ was recorded within $6 \mathrm{~min}$. The results were expressed as micromoles of trolox equivalent per $\mathrm{g}$. All determinations were carried out in triplicate.

2.10. Ferric Reducing Antioxidant Power (FRAP) Assay. The FRAP assay [33] was performed with some modifications [31]. For each analysis, $400 \mu \mathrm{L}$ of the sample $(1 \mathrm{mg} / \mathrm{mL})$ and the positive controls (rutin and quercetin, $0.05 \mathrm{mg} / \mathrm{mL}$ ) was added to $3 \mathrm{~mL}$ of the FRAP solution. The increase in absorbance at $593 \mathrm{~nm}$ was recorded in $15 \mathrm{~s}$ intervals over the course of $30 \mathrm{~min}$ at $37^{\circ} \mathrm{C}$. The FRAP results were expressed as micromoles of trolox equivalent per $\mathrm{g}$. All determinations were carried out in triplicate.

2.11. Antifungal Activity. Antifungal assays [34] were performed with some modifications as described by Ai et al. [35], Wang et al. [17], Hsu et al. [36], and Tian et al. [37]. Each extract and fraction was dissolved in different proportions of acetone and water, that is, $100 \%$ acetone for PEF, CF, $\mathrm{EAF}$, and $\mathrm{AF}$ and $50 \%$ acetone for ECE and MF. The treated dishes were incubated in the dark at $27.5-28.5^{\circ} \mathrm{C}$ for $72 \mathrm{~h}$ at moderate humidity. The relative growth inhibition (\%) of the test sample compared with the control was calculated as follows:

$$
\text { Inhibitory activity }(\%)=\left[\frac{(C-T)}{(C-4 \mathrm{~mm})}\right] \times 100 \% \text {, }
$$

where $C$ is the colony diameter of the mycelium on the control plate $(\mathrm{mm})$ and $T$ is the colony diameter of the mycelium on the test petri plate $(\mathrm{mm})$.

B. cinerea, $P$. oryzae, $P$. piricola, $G$. cingulata, and V. pyrina were chosen for growth kinetics assays. The solutions of ECE, PEF, CF, EAF, AF, and MF were serially diluted by the twofold serial dilution method and added to PDA with concentrations ranging from 6.25 to $100 \mathrm{mg} / \mathrm{mL}$. Amphotericin was used as standard. And the concentration of the sample required for $50 \%$ inhibitory activity $\left(\mathrm{EC}_{50}\right)$ was calculated using linear regression analysis. All experiments were conducted in triplicate.

2.12. Antibacterial Activity. The paper disc diffusion method, also known as the agar diffusion method, was used to detect the antibacterial activity of the extracts and fractions of the leaves of $Z$. bungeanum [38, 39]. The beef extract peptone medium was inoculated with $3 \mu \mathrm{L}$ aliquots of culture containing approximately $10^{5} \mathrm{cfu} / \mathrm{mL}$ of each organism. Sterilized filter paper discs $(5 \mathrm{~mm})$ were soaked in $5 \mathrm{~mL}$ of various concentrations (6.25 to $100 \mathrm{mg} / \mathrm{mL}$ ) of samples. Benzylpenicillin was used as standard $(0.01$ to $10 \mathrm{mg} / \mathrm{mL})$. 
The paper discs soaked in the solvent without extracts or fractions ( $80 \%$ acetone) served as black control. The MIC values were determined as the lowest concentration of extracts inhibiting visible growth of each organism on the agar plate. The soaked discs were placed in the plates and incubated for $24 \mathrm{~h}$ at $28^{\circ} \mathrm{C}$. Following the incubation period, the inhibition zones formed in the medium were measured in millimeters $(\mathrm{mm})$. All the tests were performed in triplicate and the MIC values were calculated.

2.13. Statistical Analysis. All results were expressed as the mean \pm standard deviation (SD). The significant difference was calculated by SPSS one-way ANOVA followed by Duncan's test; values $<0.05$ were considered to be significant (SPSS Inc., Chicago). The linear correlations among the various parameters were also investigated using the SPSS 18.0 software.

\section{Results and Discussion}

3.1. Total Phenolic, Flavonoid, and Alkaloid Content. The total phenolic, flavonoid, and alkaloid content of ethanol crude extracts (ECE) and its five different polarity fractions (PEF, CF, EAF, AF, and MF) from $Z$. bungeanum leaves were screened and compared. According to the results presented in Table 1, there was a statistically significant difference $(P<$ $0.05)$ among all the samples investigated. EAF exhibited the highest TFC (67.93 mmol/100 g) and TPC (97.29 mmol/100 g) followed by AF $(47.62 \mathrm{mmol} / 100 \mathrm{~g}$ for TFC; $62.87 \mathrm{mmol} / 100 \mathrm{~g}$ for TPC), which were much higher than ECE and other fractions. Compared with the high flavonoid and phenolic content, alkaloid yields were the lowest, since this group of compounds is sparsely distributed and more specific of genera and species [40]. Among the extracts and fractions of $Z$. bungeanum leaves, CF exhibited the greatest TAC $(4.39 \mathrm{mmol} / 100 \mathrm{~g})$ followed by PEF $(1.71 \mathrm{mmol} / 100 \mathrm{~g})$. Chen et al. reported that 23 alkaloids were isolated from the $\mathrm{CHCl}_{3}$ and $\mathrm{MeOH}$ extracts of the root bark of $Z$. simulans [41]. Ren and Xie reported 6 alkaloids from the root of $Z$. bungeanum [42]. We can hypothesize that CF from the leaves of $Z$. bungeanum can be further fractioned to gain bioactive alkaloids.

3.2. HPLC Analysis of the Extracts and Fractions. As seen in Table 2, the linear regression results indicated good linear correlation by the correlation coefficients between 0.9991 and 0.9999 for all of the standard compounds within the appropriate concentration ranges. The precision of the analytical method was analyzed in triplicate for three times within one day, while for interday variability, the samples were examined in triplicate for three consecutive days, and the RSDs of the peak areas were estimated to be $0.71-1.51 \%$ $(n=6)$. The repeatability of the method was determined by injecting the ECE for six times, while the peak area of the twelve detected compounds was recorded, and the RSDs of their peak area varied from 0.16 to $2.94 \%$. To confirm the accuracy of the method, a recovery experiment was performed by mixing quantified samples with specific quantities of standard compounds. The average percentages of recovery of the twelve standard compounds ranged from 98.37 to $103.76 \%$. In addition, the RSDs varied from 0.35 to $1.66 \%(n=6)$. All the results demonstrated that the conditions of the analysis were repeatable and accurate.

The content of twelve compounds in the extracts and its five fractions from $Z$. bungeanum leaves were determined by matching their retention times against those of the standards (Table 3). Good correlation was observed between the peak area and the content. We established a standard HPLC method to determine 12 phytochemicals from the leaves of $Z$. bungeanum simultaneously. Epicatechin $(27.45 \mathrm{mg} / \mathrm{g})$, rutin $(16.86 \mathrm{mg} / \mathrm{g})$, hyperoside $(19.25 \mathrm{mg} / \mathrm{g})$, quercitrin $(16.73 \mathrm{mg} / \mathrm{g})$, chlorogenic acid (3.78 mg/g), kaempferol-3-rhamnoside (3.75 mg/g), trifolin $(4.53 \mathrm{mg} / \mathrm{g})$, and sesamin $(5.13 \mathrm{mg} / \mathrm{g})$ were the major phenolic components in ECE, other compounds (quercetin, nitidine chloride, chelerythrine, and xanthyletin) had a lower level of content (less than $1 \mathrm{mg} / \mathrm{g}$ ). Among the 5 subfractions, the EAF exhibited the highest content of quercitrin (125.21 mg/g), kaempferol-3-rhamnoside (54.95 mg/g), quercetin $(24.36 \mathrm{mg} / \mathrm{g})$, nitidine chloride $(0.20 \mathrm{mg} / \mathrm{g})$, and sesamin $(26.24 \mathrm{mg} / \mathrm{g})$. The AF exhibited the highest content of chlorogenic acid $(5.87 \mathrm{mg} / \mathrm{g})$, rutin $(29.94 \mathrm{mg} / \mathrm{g})$, hyperoside $(98.33 \mathrm{mg} / \mathrm{g})$, and trifolin $(31.24 \mathrm{mg} / \mathrm{g})$. The CF exhibited the highest content of xanthyletin $(0.09 \mathrm{mg} / \mathrm{g})$, while the MF had the highest content of epicatechin $(39.32 \mathrm{mg} / \mathrm{g})$ and chelerythrine $(0.09 \mathrm{mg} / \mathrm{g})$. It is indicated that the major phytochemicals, especially phenolic compounds, were concentrated in EAF and AF, which may result from the enrichment effects during chromatographic fractionation. And we hypothesized that these bioactive phytochemicals might be responsible for their profound bioproperties.

Chromatography of the ECE and its five different polarity fractions revealed that there are significant differences among the tested samples (Figure 1(b)). Figure 1(a) was the HPLC chromatograms of the 12 standard compounds. ECE contained all the phytochemicals detected and exhibited the richest peaks. But further fractionation of ECE by column chromatography on silica gel produced five subfractions with even higher content of all the detected phytochemicals. Among the five subfractions, peaks 1-9 (chlorogenic acid, epicatechin, rutin, hyperoside, trifolin, quercitrin, kaempferol-3rhamnoside, quercetin, and nitidine chloride) were common peaks in EAF and AF. Peak 7 (kaempferol-3-rhamnoside), peak 11 (xanthyletin), and peaks $12-15$ were common peaks detected in PEF and CF. The peak area of peaks 11-14 was the greatest in CF. Finally, peaks 1-6 (chlorogenic acid, epicatechin, rutin, hyperoside, trifolin, and quercitrin) and peak 10 (chelerythrine) were detected in MF at low levels, except for peak 2 .

The present results exhibited significant differences with the reported study on the phytochemical composition of the Z. bungeanum leaves of Hebei, China [1]. Three major compounds (trifolin, kaempferol-3-rhamnoside, and quercetin) detected in the $Z$. bungeanum leaves of Taibai were not identified in that of Hebei. Nevertheless, other major phytochemicals, such as chlorogenic acid, epicatechin, rutin, hyperoside, 
TABLE 1: Content of total flavonoid, phenolic, and alkaloid and antioxidant capacity of ethanol extracts and its five fractions from $Z$. bungeanum leaves.

\begin{tabular}{|c|c|c|c|c|c|c|}
\hline \multirow[b]{2}{*}{ Samples } & \multicolumn{3}{|c|}{ Content } & \multicolumn{3}{|c|}{ Antioxidant capacity } \\
\hline & $\begin{array}{c}\text { TFC } \\
(\mathrm{mmol} \mathrm{QE} / 100 \mathrm{~g})\end{array}$ & $\begin{array}{c}\text { TPC } \\
(\mathrm{mmol} \mathrm{GAE} / 100 \mathrm{~g})\end{array}$ & $\begin{array}{c}\text { TAC } \\
(\mathrm{mmol} \mathrm{CE} / 100 \mathrm{~g})\end{array}$ & $\mathrm{DPPH}_{\mathrm{IC} 50}(\mu \mathrm{g} / \mathrm{mL})$ & $\begin{array}{c}\text { FRAP } \\
(\mu \mathrm{mol} \text { Trolox } / \mathrm{g})\end{array}$ & $\begin{array}{c}\text { ABTS } \\
(\mu \mathrm{mol} \text { Trolox } / \mathrm{g})\end{array}$ \\
\hline ECE & $60.96 \pm 8.87^{\mathrm{a}}$ & $58.78 \pm 9.37^{\mathrm{b}}$ & $0.47 \pm 0.28^{\mathrm{c}}$ & $40.75 \pm 0.21^{c}$ & $317.11 \pm 9.71^{\mathrm{b}}$ & $1122.91 \pm 34.62^{c}$ \\
\hline PEF & $4.01 \pm 3.42^{\mathrm{d}}$ & $4.43 \pm 2.17^{\mathrm{c}}$ & $1.71 \pm 0.07^{\mathrm{b}}$ & $377.95 \pm 39.39^{f}$ & $81.56 \pm 7.41^{\mathrm{e}}$ & $264.20 \pm 37.27^{\mathrm{f}}$ \\
\hline $\mathrm{CF}$ & $2.29 \pm 2.03^{\mathrm{d}}$ & $7.07 \pm 2.36^{\mathrm{c}}$ & $4.39 \pm 0.05^{\mathrm{a}}$ & $169.15 \pm 4.60^{\mathrm{e}}$ & $170.44 \pm 10.45^{\mathrm{d}}$ & $563.86 \pm 22.66^{\mathrm{e}}$ \\
\hline EAF & $67.93 \pm 9.29^{a}$ & $97.29 \pm 17.53^{\mathrm{a}}$ & $0.25 \pm 0.02^{\mathrm{c}}$ & $13.20 \pm 0.85^{\mathrm{b}}$ & $615.88 \pm 1.86^{\mathrm{b}}$ & $2147.83 \pm 23.08^{b}$ \\
\hline $\mathrm{AF}$ & $47.62 \pm 6.34^{b c}$ & $62.87 \pm 10.80^{\mathrm{b}}$ & $0.06 \pm 0.01^{\mathrm{c}}$ & $18.55 \pm 0.35^{\mathrm{b}}$ & $594.15 \pm 8.89^{\mathrm{b}}$ & $2044.58 \pm 19.99^{\mathrm{b}}$ \\
\hline MF & $31.63 \pm 5.30^{c}$ & $8.35 \pm 0.30^{\mathcal{c}}$ & $0.10 \pm 0^{c}$ & $85.85 \pm 2.19^{d}$ & $191.93 \pm 2.22^{\mathrm{d}}$ & $747.69 \pm 38.77^{\mathrm{d}}$ \\
\hline Quercetin & - & - & - & $2.60 \pm 0.10^{\mathrm{a}}$ & $1865.80 \pm 33.40^{\mathrm{a}}$ & $20113.58 \pm 23.20^{\mathrm{a}}$ \\
\hline Rutin & - & - & - & $10.42 \pm 0.14^{\mathrm{ab}}$ & $1722.59 \pm 6.42^{\mathrm{a}}$ & $20153.46 \pm 46.05^{a}$ \\
\hline
\end{tabular}

TFC expressed as mmol quercetin equivalent per $100 \mathrm{~g}$. TPC expressed as mmol gallic acid equivalent per $100 \mathrm{~g}$. TAC expressed as mmol chelerythrine equivalent per $100 \mathrm{~g}$. DPPH $\mathrm{IC}_{50}$ values were the effective concentrations at which DPPH radicals were scavenged by $50 \%$. FRAP and ABTS results expressed as micromoles of trolox equivalent per $\mathrm{g}$. Values are the mean of three replicates \pm SD. Means with different letters within a column were significantly different $(P<0.05)$.

and quercitrin, were both detected in the Z. bungeanum leaves of Taibai and in that of Hebei, though the contents were significantly different. The main reasons for these variations may be some geographical differences and gene mutation $[43,44]$. Further isolation and purification of the fractions (EAF, AF, and CF) with the richest phytochemicals ought to be conducted, and later chemical structures of the new bioactive compounds need to be analyzed.

3.3. DPPH Radical Scavenging Activity. In the present study, the ethanol crude extracts (ECE) and its five different polarity fractions showed DPPH radical scavenging activity in a dose dependent manner at concentration of $20-1000 \mu \mathrm{g} / \mathrm{mL}$ (Figure 2). The EAF and AF exhibited higher DPPH radical scavenging activity than ECE and other fractions. In order to further quantify the DPPH radical scavenging activity, the $\mathrm{IC}_{50}$ values of the extracts and five fractions were determined and shown in Table 1. All the extracts and fractions showed significant $(P<0.05)$ differences in their ability to reduce the $\mathrm{DPPH}$ radical; EAF and AF were selected as the most effective fractions with the highest DPPH radical scavenging ability, which were not significantly different with the reference compound (rutin, $\mathrm{IC}_{50}=10.42 \mu \mathrm{g} / \mathrm{mL}$ ). As seen in Table 1 , the $\mathrm{IC}_{50}$ value of EAF was $13.20 \mu \mathrm{g} / \mathrm{mL}$, which was not significantly different from that of $\mathrm{AF}(18.55 \mu \mathrm{g} / \mathrm{mL})$ but was 3.1-, 6.5-, 12.8-, and 28.6-fold lower than that of ECE, MF, CF, and PEF, respectively $(P<0.05)$. Because the antioxidant activities were inversely correlated with the $\mathrm{IC}_{50}$ values, the DPPH radical-scavenging activity, in decreasing order, was $\mathrm{EAF}>\mathrm{AF}>\mathrm{MF}>\mathrm{CF}>\mathrm{PEF}$.

3.4. ABTS Radical Cation Decolorization Activity. Another effective method to measure radical scavenging activity is the ABTS radical cation decolorization assay, which showed similar results to those obtained in the DPPH reaction. The scavenging activity of the extracts on free radical ABTS generated by potassium persulfate was compared with a standard amount of trolox. The result was calculated as micromoles of trolox equivalent per g. The ABTS radical scavenging ability of the extracts and fractions from $Z$. bungeanum leaves compared to rutin and quercetin has been depicted in Table 1; we also found that EAF and AF were the most effective fractions with the highest ABTS radical scavenging abilities. The ABTS radical scavenging ability of EAF was $2147.83 \mu \mathrm{mol}$ Trolox/g, which was not significantly different from that of AF $(2044.58 \mu \mathrm{mol}$ Trolox $/ \mathrm{g}, P<0.05)$ but was 1.9-, 2.9-, 3.8-, and 8.1-fold higher than that of ECE, MF, CF, and PEF, respectively $(P<0.05)$.

3.5. Ferric Reducing Antioxidant Power (FRAP). The FRAP values of the extracts and fractions from $Z$. bungeanum leaves have been depicted in Table 1 . EAF and AF were also screened as the most effective fractions with the highest reducing values, which were rather consistent with the results of the scavenging capacity on DPPH and ABTS radical. It is exhibited that the reducing ability of EAF was $615.88 \mu \mathrm{mol}$ Trolox/g, which was not significantly different from that of AF $(594.15 \mu \mathrm{mol}$ Trolox/g, $P<0.05)$ but was 1.9-, 3.2-, 3.6-, and 7.6-fold higher $(P<0.05)$ than that of ECE, MF, CF, and $\mathrm{PEF}$, respectively.

3.6. Correlation between the Total Phenolic and Flavonoid Content and the Antioxidant Assays. Based on the correlation matrix (Table 4), each coefficient was assessed to establish the correlations between different assays. As displayed in Table 4, a high correlation was observed among the three methods for antioxidant activity measurement $(-0.777 \leq r \leq$ $0.999, P<0.01$ ), indicating a great degree of equivalence among the measurements. Okonogi et al. demonstrated that the relationship between ABTS radical scavenging activities and the $\mathrm{DPPH}_{\mathrm{IC} 50}$ of the samples was nonlinear $(r=-0.797)$. However, the logarithmic values of $\mathrm{DPPH}_{\mathrm{IC} 50}$ against ABTS radical scavenging activities gave good linearity $(r=-0.968)$ [45]. Thus, the ABTS result was in good agreement with that of the DPPH assay; among the evaluated extracts and fractions, EAF and AF were selected as two fractions with the highest free radical and hydroxyl radical-scavenging activities. The FRAP values exhibited a significant linear 


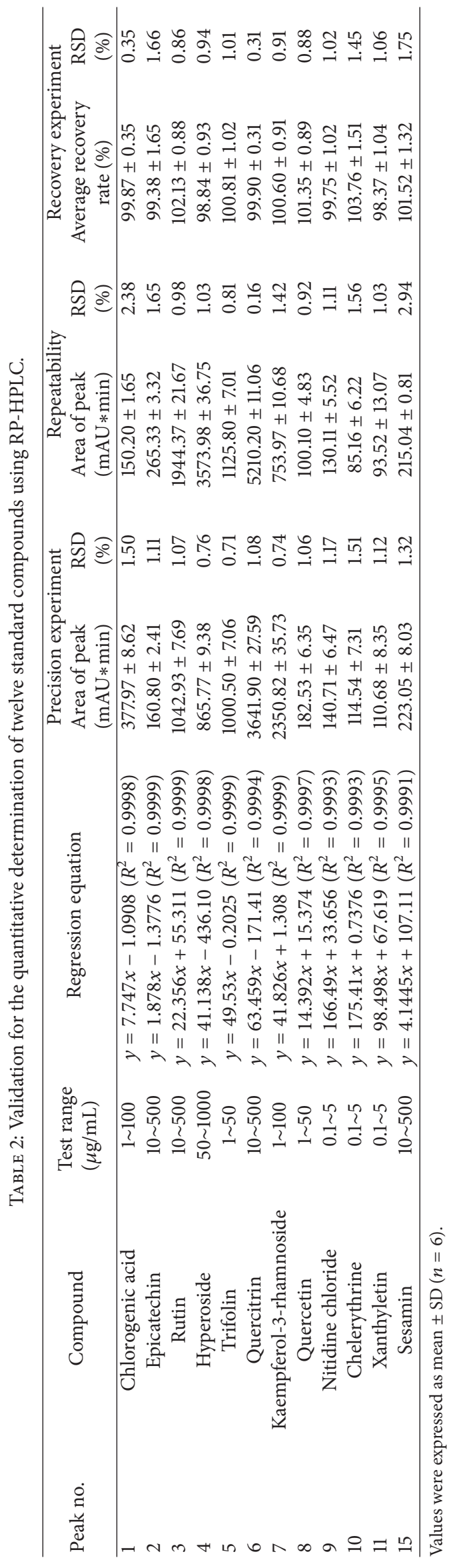


TABLE 3: Content of twelve compounds in extracts and five fractions from Z. bungeanum leaves.

\begin{tabular}{|c|c|c|c|c|c|c|c|}
\hline \multirow{2}{*}{ Peak no. } & \multirow{2}{*}{ Compounds } & \multicolumn{6}{|c|}{ Content $(\mathrm{mg} / \mathrm{g})$} \\
\hline & & ECE & PEF & $\mathrm{CF}$ & EAF & $\mathrm{AF}$ & MF \\
\hline 1 & Chlorogenic acid & $3.78 \pm 0.12^{\mathrm{b}}$ & $\mathrm{ND}$ & ND & $2.96 \pm 0.06^{\mathrm{b}}$ & $5.87 \pm 0.10^{\mathrm{a}}$ & $2.40 \pm 0.11^{\mathrm{d}}$ \\
\hline 2 & Epicatechin & $27.45 \pm 0.93^{c}$ & ND & ND & $33.12 \pm 0.61^{\mathrm{b}}$ & $27.42 \pm 0.17^{\mathfrak{c}}$ & $39.32 \pm 1.30^{\mathrm{a}}$ \\
\hline 3 & Rutin & $16.86 \pm 0.26^{\mathrm{b}}$ & ND & ND & $4.79 \pm 0.03^{\mathrm{d}}$ & $29.94 \pm 0.01^{\mathrm{a}}$ & $14.72 \pm 0.09^{c}$ \\
\hline 4 & Hyperoside & $19.25 \pm 0.55^{\mathrm{c}}$ & ND & ND & $24.17 \pm 0.90^{\mathrm{b}}$ & $98.33 \pm 1.14^{\mathrm{a}}$ & $11.97 \pm 0.10^{\mathrm{d}}$ \\
\hline 5 & Trifolin & $4.53 \pm 0.07^{\mathrm{c}}$ & ND & ND & $21.22 \pm 0.12^{\mathrm{b}}$ & $31.24 \pm 0.78^{\mathrm{a}}$ & $1.03 \pm 0.01^{\mathrm{d}}$ \\
\hline 6 & Quercitrin & $16.73 \pm 0.97^{\mathrm{c}}$ & ND & ND & $125.21 \pm 0.90^{\mathrm{a}}$ & $116.63 \pm 1.42^{\mathrm{b}}$ & $2.49 \pm 0.09^{\mathrm{d}}$ \\
\hline 7 & Kaempferol-3-rhamnoside & $3.75 \pm 0.02^{\mathrm{c}}$ & $0.48 \pm 0.01^{\mathrm{e}}$ & $1.23 \pm 0.02^{\mathrm{d}}$ & $54.95 \pm 0.95^{\mathrm{a}}$ & $16.71 \pm 0.49^{\mathrm{b}}$ & ND \\
\hline 8 & Quercetin & $0.76 \pm 0.03^{\mathrm{b}}$ & ND & ND & $24.36 \pm 0.71^{\mathrm{a}}$ & $0.90 \pm 0.05^{\mathrm{b}}$ & ND \\
\hline 9 & Nitidine chloride & $0.18 \pm 0.003^{\mathrm{a}}$ & ND & ND & $0.20 \pm 0.004^{\mathrm{a}}$ & $0.06 \pm 0.003^{b}$ & ND \\
\hline 10 & Chelerythrine & $0.09 \pm 0.002^{\mathrm{a}}$ & ND & ND & ND & $0.08 \pm 0.005^{\mathrm{a}}$ & $0.09 \pm 0.003^{\mathrm{a}}$ \\
\hline 11 & Xanthyletin & $0.06 \pm 0.01^{\mathrm{b}}$ & $0.08 \pm 0.01^{\mathrm{b}}$ & $0.09 \pm 0.01^{\mathrm{a}}$ & $0.07 \pm 0.005^{c}$ & ND & ND \\
\hline 15 & Sesamin & $5.13 \pm 0.11^{\mathrm{c}}$ & $1.20 \pm 0.14^{\mathrm{d}}$ & $8.09 \pm 1.07^{\mathrm{b}}$ & $26.24 \pm 0.87^{\mathrm{a}}$ & ND & ND \\
\hline
\end{tabular}

Values are the mean of three replicates $\pm \mathrm{SD}$. Means with different letters within a row were significantly different $(P<0.05)$. ND: not detectable.

TABLE 4: Correlation matrix between the results of the total phenolic and flavonoid content and the FRAP, ABTS, and DPPH activities.

\begin{tabular}{lcccccc}
\hline & $\log$ DPPH & DPPH & ABTS & FRAP & TPC & TFC \\
\hline $\log$ DPPH & 1 & & & & & \\
DPPH & $-0.909^{*}$ & 1 & & & & \\
ABTS & $-0.968^{* *}$ & -0.797 & 1 & & & \\
FRAP & $-0.958^{* *}$ & -0.777 & $0.999^{* *}$ & 1 & & \\
TPC & $-0.916^{*}$ & $-0.829^{*}$ & $0.827^{*}$ & 0.808 & 1 & \\
TFC & $-0.922^{* *}$ & -0.724 & $0.924^{* *}$ & $0.923^{* *}$ & $0.908^{*}$ & 1 \\
\hline
\end{tabular}

*Correlation is significant at the 0.05 level; ${ }^{* *}$ correlation is significant at the 0.01 level.

correlation with ABTS result $(r=0.999, P<0.01)$ and $\log$ values of $\mathrm{DPPH}_{\mathrm{IC} 50}(r=-0.958, P<0.01)$, indicating that the phytochemicals with radical scavenging abilities also possessed reducing abilities. $\log \mathrm{DPPH}_{\mathrm{IC} 50}$, ABTS, and FRAP results were significantly correlated with the TFC $(r=-0.922$ for $\log \mathrm{DPPH}_{\mathrm{IC} 50}, P<0.01 ; r=0.924$ for ABTS, $P<0.01$; $r=0.923$ for FRAP, $P<0.01$ ). According to Prior and others [46] and Huang and others [47], the Folin-Ciocalteu method (used for determination of the total phenolic content) is based on oxidation-reduction reactions (single electron transfer (SET)) and can thus be considered as one of the methods for the determination of antioxidant activity. In addition, in our present study, good correlations were also observed between the TPC and $\log \mathrm{DPPH}_{\mathrm{IC} 50}$ or ABTS results $(r=-0.916$ for $\log \mathrm{DPPH}_{\mathrm{IC} 50}, P<0.05 ; r=0.827$ for ABTS, $\left.P<0.05\right)$.

In our present study, it can be inferred that EAF and $\mathrm{AF}$ contained the highest total polyphenol and flavonoid levels and exhibited the highest antioxidant capacity among the five different polarity fractions. Since the antioxidant activity of plants depend on the amount and type of phenolic compounds that occur in them [48], we hypothesized that the phenolic compounds of the analyzed extracts and fractions were responsible for the profound antioxidant effects. Due to the enrichment effects during the chromatography fractionation, $\mathrm{EAF}$ and $\mathrm{AF}$ were effective in the recuperation of compounds with good reducing capacity and good electron donors.

3.7. Antifungal Activity. The antifungal activity of ECE, PEF, $\mathrm{CF}, \mathrm{EAF}, \mathrm{AF}$, and MF against 20 varieties of plant pathogenic fungi was studied using the mycelial growth method. The inhibition of ECE ranged between 6.00 and $65.22 \%$, while those of PEF, CF, EAF, AF, and MF were between 10.00 and $70.00 \%$ at a concentration of $50 \mathrm{mg} / \mathrm{mL}$. Five plant pathogenic fungi (B. cinerea, P. oryzae, P. piricola, G. cingulata, and V. pyrina) with higher antifungal activity (over 50\%) were chosen for further growth kinetics assays (Table 5).

The antifungal kinetics of extracts and fractions of $Z$. bungeanum leaves were tested on the five selected fungi. The phytochemicals of $Z$. bungeanum leaves inhibited fungal growth $(2.32-92.10 \%)$ at concentrations of $6.25-100 \mathrm{mg} / \mathrm{mL}$ (Figure 3). The growth inhibition of each sample increased with concentration and then plateaued, notwithstanding the increases in concentration. At $100 \mathrm{mg} / \mathrm{mL}$ concentrations of $\mathrm{CF}$ and EAF, the inhibitory activity of $G$. cingulata was $90.79 \%$ and $92.10 \%$, respectively (Figures 3(c) and 3(d)). At $50 \mathrm{mg} / \mathrm{mL}$ concentrations, significant inhibitory activity (above 50\%) was also observed for ECE, PEF, CF, EAF, and AF (Figures 3(a), 3(b), 3(c), 3(d), and 3(e)), indicating that the phytochemicals of $Z$. bungeanum leaves possessed broad-spectrum antifungal property; yet the MF (Figure 3(f)) exhibited less inhibitory activity (less than $50 \%$ ) than the five selected pathogenic fungi. Amphotericin was used as the positive control (Figure $3(\mathrm{~g})$ ).

As seen in Table 6, the CF, with the lowest $\mathrm{EC}_{50}$ values of $0.83,9.39,4.18,10.89$, and $5.35 \mathrm{mg} / \mathrm{mL}$ against the growth of G. cingulata, B. cinerea, P. oryzae, $P$. piricola, and V. pyrina separately, exhibited the greatest inhibitory activity closely followed by EAF, with $\mathrm{EC}_{50}$ values of $9.25,24.39,17.81,13.73$, and $8.11 \mathrm{mg} / \mathrm{mL}$, respectively $(P<0.05)$. CF and EAF exhibited greater antifungal activities, which might be further studied to determine whether this activity can be retained in vivo. The fractions (CF and $\mathrm{EAF}$ ) with low and medium polarity phytochemicals exhibited the highest antifungal 
TABLE 5: Preliminary antifungal activity of ethanol extracts and its five fractions from Z. bungeanum leaves tested at $50 \mathrm{mg} / \mathrm{mL}$ against 20 plant pathogenic fungi.

\begin{tabular}{|c|c|c|c|c|c|c|}
\hline \multirow{2}{*}{ Species } & \multicolumn{6}{|c|}{ Inhibitory activity (\%) } \\
\hline & ECE & PEF & $\mathrm{CF}$ & EAF & $\mathrm{AF}$ & MF \\
\hline Alternaria alternata & $30.91 \pm 1.57^{\mathrm{c}}$ & $28.18 \pm 1.57^{\mathrm{C}}$ & $34.55 \pm 0.00^{\mathrm{b}}$ & $43.64 \pm 1.57^{\mathrm{a}}$ & $36.36 \pm 3.15^{\mathrm{b}}$ & $17.27 \pm 1.57^{\mathrm{d}}$ \\
\hline Alternaria brassicae & $65.22 \pm 3.77^{\mathrm{ab}}$ & $60.87 \pm 5.65^{b c}$ & $69.57 \pm 1.88^{\mathrm{a}}$ & $63.04 \pm 3.77^{\mathrm{abc}}$ & $57.61 \pm 3.26^{c}$ & $60.87 \pm 3.26^{b c}$ \\
\hline Alternaria solani & $29.51 \pm 1.42^{\mathrm{d}}$ & $34.43 \pm 1.42^{c}$ & $41.80 \pm 1.42^{\mathrm{b}}$ & $46.72 \pm 1.42^{\mathrm{a}}$ & $40.98 \pm 2.46^{\mathrm{b}}$ & $23.77 \pm 2.46^{\mathrm{e}}$ \\
\hline Bipolaris sorokiniana & $24.55 \pm 1.57^{\mathrm{c}}$ & $27.27 \pm 4.17^{\mathfrak{c}}$ & $35.45 \pm 1.57^{\mathrm{b}}$ & $50.91 \pm 2.73^{\mathrm{a}}$ & $28.18 \pm 1.57^{\mathrm{c}}$ & $24.55 \pm 3.15^{\mathrm{c}}$ \\
\hline Botrytis cinerea & $38.76 \pm 1.34^{\mathrm{cd}}$ & $42.64 \pm 2.69^{c}$ & $60.47 \pm 2.33^{\mathrm{a}}$ & $62.79 \pm 2.33^{\mathrm{a}}$ & $49.61 \pm 5.85^{\mathrm{b}}$ & $34.88 \pm 6.15^{\mathrm{d}}$ \\
\hline Cladosporium fulvum & $29.03 \pm 5.59^{c}$ & $41.94 \pm 2.42^{\mathrm{b}}$ & $50.81 \pm 1.40^{\mathrm{a}}$ & $50.81 \pm 1.40^{\mathrm{a}}$ & $43.55 \pm 1.40^{\mathrm{b}}$ & $25.00 \pm 0.00^{c}$ \\
\hline Colletotrichum gloeosporioides & $28.18 \pm 4.17^{\mathrm{c}}$ & $29.09 \pm 5.45^{\mathrm{C}}$ & $37.27 \pm 2.73^{\mathrm{b}}$ & $52.73 \pm 4.17^{\mathrm{a}}$ & $29.09 \pm 2.73^{c}$ & $16.36 \pm 1.57^{\mathrm{d}}$ \\
\hline Cucumis dahlia & $25.47 \pm 1.63^{c}$ & $35.85 \pm 1.63^{\mathrm{b}}$ & $43.40 \pm 2.83^{\mathrm{a}}$ & $34.91 \pm 2.83^{\mathrm{b}}$ & $34.91 \pm 2.83^{b}$ & $23.58 \pm 2.83^{c}$ \\
\hline Dothiorella gregaria & $45.38 \pm 1.33^{\mathrm{d}}$ & $52.31 \pm 1.33^{\mathrm{c}}$ & $70.00 \pm 2.31^{\mathrm{a}}$ & $62.31 \pm 3.53^{\mathrm{b}}$ & $46.15 \pm 1.33^{\mathrm{d}}$ & $44.62 \pm 6.11^{\mathrm{d}}$ \\
\hline Fusarium oxysporum & $36.84 \pm 2.63^{c}$ & $25.44 \pm 1.52^{\mathrm{d}}$ & $35.09 \pm 1.52^{\mathrm{c}}$ & $58.77 \pm 3.04^{\mathrm{a}}$ & $42.11 \pm 0.11^{\mathrm{b}}$ & $27.19 \pm 1.52^{\mathrm{d}}$ \\
\hline Glomerella cingnlata & $50.00 \pm 2.63^{c}$ & $53.51 \pm 5.48^{\mathrm{bc}}$ & $55.26 \pm 0.00^{\mathrm{b}}$ & $64.04 \pm 1.52^{\mathrm{a}}$ & $49.12 \pm 1.52^{\mathrm{c}}$ & $37.72 \pm 1.52^{\mathrm{d}}$ \\
\hline Phacidiopycnis washingtonensis & $24.14 \pm 2.99^{c}$ & $25.00 \pm 2.59^{c}$ & $35.34 \pm 2.59^{\mathrm{b}}$ & $50.00 \pm 1.49^{\mathrm{a}}$ & $37.07 \pm 1.49^{b}$ & $35.34 \pm 2.59^{\mathrm{b}}$ \\
\hline Physalospora piricola & $43.75 \pm 8.33^{\mathrm{bc}}$ & $45.83 \pm 5.51^{b c}$ & $51.39 \pm 1.20^{\mathrm{b}}$ & $60.42 \pm 2.08^{\mathrm{a}}$ & $51.39 \pm 3.18^{\mathrm{b}}$ & $40.97 \pm 1.20^{c}$ \\
\hline Piricularia oryzae & $42.22 \pm 4.44^{\mathrm{d}}$ & $51.85 \pm 2.57^{\mathrm{c}}$ & $68.15 \pm 1.28^{\mathrm{a}}$ & $60.74 \pm 1.28^{\mathrm{b}}$ & $49.63 \pm 1.28^{\mathrm{c}}$ & $43.70 \pm 1.28^{\mathrm{d}}$ \\
\hline Rhizoctonia cerealis & $6.00 \pm 3.46^{\mathrm{b}}$ & $10.00 \pm 6.00^{\mathrm{b}}$ & $28.00 \pm 6.00^{\mathrm{a}}$ & $34.00 \pm 6.00^{\mathrm{a}}$ & $24.00 \pm 3.46^{\mathrm{a}}$ & $26.00 \pm 9.17^{\mathrm{a}}$ \\
\hline Sclerotinia sclerotiorum & $19.89 \pm 1.70^{\mathrm{d}}$ & $56.82 \pm 2.60^{\mathrm{b}}$ & $59.66 \pm 2.60^{\mathrm{ab}}$ & $64.20 \pm 1.70^{\mathrm{a}}$ & $29.55 \pm 4.92^{\mathrm{c}}$ & $26.70 \pm 2.95^{\mathrm{c}}$ \\
\hline Thanatephorus cucumeris & $31.03 \pm 3.95^{\mathrm{d}}$ & $37.93 \pm 2.59^{b c}$ & $34.48 \pm 3.95^{\mathrm{bcd}}$ & $40.52 \pm 4.48^{\mathrm{a}}$ & $33.62 \pm 2.99^{\mathrm{cd}}$ & $32.76 \pm 2.59^{\mathrm{cd}}$ \\
\hline Valsa mali & $23.64 \pm 2.73^{c}$ & $26.36 \pm 2.73^{c}$ & $42.73 \pm 2.73^{\mathrm{b}}$ & $50.91 \pm 2.73^{\mathrm{a}}$ & $39.09 \pm 4.17^{\mathrm{b}}$ & $15.45 \pm 2.73^{\mathrm{d}}$ \\
\hline Venturia pyrina & $54.62 \pm 2.66^{\mathrm{a}}$ & $47.69 \pm 1.33^{\mathrm{b}}$ & $56.92 \pm 3.53^{\mathrm{a}}$ & $58.46 \pm 0.00^{\mathrm{a}}$ & $54.62 \pm 1.33^{\mathrm{a}}$ & $37.69 \pm 2.31^{\mathrm{c}}$ \\
\hline Verticillium dahliae & $24.07 \pm 3.21^{\mathrm{b}}$ & $21.30 \pm 5.78^{b}$ & $35.19 \pm 1.60^{\mathrm{a}}$ & $37.96 \pm 3.21^{\mathrm{a}}$ & $34.26 \pm 1.60^{\mathrm{a}}$ & $23.15 \pm 1.60^{b}$ \\
\hline
\end{tabular}

Values are the mean of three replicates $\pm \mathrm{SD}$. Means with different letters within a row were significantly different $(P<0.05)$.

TABLE 6: $\mathrm{EC}_{50}$ values of ethanol extracts and its five fractions from $Z$. bungeanum leaves against 5 selected plant pathogenic fungi.

\begin{tabular}{lccccc}
\hline Sample & & $\mathrm{EC}_{50}(\mathrm{mg} / \mathrm{mL})$ & & \\
& Botrytis cinerea & Piricularia oryzae & Physalospora piricola & Glomerella cingulata & Venturia pyrina \\
\hline ECE & $11.82 \pm 1.15^{\mathrm{ab}}$ & $12.31 \pm 0.45^{\mathrm{a}}$ & $39.48 \pm 2.25^{\mathrm{ab}}$ & $13.00 \pm 1.34^{\mathrm{bc}}$ & $33.22 \pm 3.61^{\mathrm{d}}$ \\
PEF & $69.34 \pm 3.99^{\mathrm{d}}$ & $30.02 \pm 3.25^{\mathrm{ab}}$ & $65.32 \pm 2.39^{\mathrm{b}}$ & $32.83 \pm 4.61^{\mathrm{d}}$ & $31.77 \pm 0.77^{\mathrm{cd}}$ \\
CF & $9.39 \pm 0.17^{\mathrm{ab}}$ & $4.18 \pm 0.08^{\mathrm{a}}$ & $10.89 \pm 1.62^{\mathrm{ab}}$ & $0.83 \pm 0.24^{\mathrm{a}}$ & $5.35 \pm 0.34^{\mathrm{ab}}$ \\
EAF & $24.39 \pm 2.38^{\mathrm{b}}$ & $17.81 \pm 0.19^{\mathrm{a}}$ & $13.73 \pm 0.69^{\mathrm{ab}}$ & $9.25 \pm 0.11^{\mathrm{b}}$ & $8.11 \pm 0.74^{\mathrm{b}}$ \\
AF & $51.16 \pm 3.54^{\mathrm{c}}$ & $75.63 \pm 18.53^{\mathrm{b}}$ & $46.69 \pm 11.08^{\mathrm{ab}}$ & $14.96 \pm 1.11^{\mathrm{c}}$ & $26.44 \pm 3.11^{\mathrm{c}}$ \\
MF & $598.31 \pm 18.91^{\mathrm{e}}$ & $625.81 \pm 49.58^{\mathrm{c}}$ & $646.04 \pm 56.20^{\mathrm{c}}$ & $227.90 \pm 2.64^{\mathrm{e}}$ & $110.18 \pm 4.15^{\mathrm{e}}$ \\
Amphotericin & $0.03^{\mathrm{a}}$ & $0.01^{\mathrm{a}}$ & $0.08^{\mathrm{a}}$ & $0.01^{\mathrm{a}}$ & $0.37^{\mathrm{a}}$ \\
\hline
\end{tabular}

Values are the mean of three replicates $\pm \mathrm{SD}$. Means with different letters within a column were significantly different $(P<0.05)$.

activities. These results have shown that CF and EAF from $Z$. bungeanum leaves might be an attractive alternative for the use of a natural product for control of fungi that attack food and crops, avoiding fungicides application.

3.8. Antibacterial Activity. MIC values of extracts and fractions of $Z$. bungeanum leaves were shown in Table 7 . The control (80\% acetone) did not inhibit any of microorganisms tested. The EAF showed the best antibacterial activity against both Gram-positive and Gram-negative bacteria, $S$. aureus $(2.38 \mathrm{mg} / \mathrm{mL})$, E. coli $(2.32 \mathrm{mg} / \mathrm{mL})$, and B. subtilis $(4.24 \mathrm{mg} / \mathrm{mL})$, and were not significantly different from those of $\operatorname{MF}(2.65,3.10$, and $4.10 \mathrm{mg} / \mathrm{mL}$, resp.). Benzylpenicillin was only effective in the inhibition of Gram-positive bacteria. With the rapid emergence of multiple drug resistant pathogenic strains and the adverse side effects due to the use of conventional antibiotics, the discovery of new antimicrobial agents is a vital aspect of research and development in the realm of public health [49]. It is promising that EAF from $Z$. bungeanum leaves may harbor therapeutic compounds with significant antibacterial activity.

\section{Conclusions}

Phytochemical profiles and bioactivities of extracts and fractions from the leaves of $Z$. bungeanum were studied. Based on our results, EAF, AF, and CF were selected as the most effective fractions due to higher phytochemical contents and significant bioactivities. Moreover, a simple, rapid, and effective HPLC procedure for simultaneous quantification of 
TABLE 7: MIC values of ethanol extracts and its five fractions from Z. bungeanum leaves against 3 selected bacteria.

\begin{tabular}{|c|c|c|c|c|c|c|c|}
\hline \multirow{2}{*}{ Bacteria } & \multicolumn{7}{|c|}{$\mathrm{MIC}(\mathrm{mg} / \mathrm{mL})$} \\
\hline & ECE & PEF & CF & EAF & $\mathrm{AF}$ & MF & Benzylpenicillin \\
\hline Staphylococcus aureus & $4.93 \pm 0.69^{c}$ & $2.45 \pm 1.25^{\mathrm{b}}$ & $4.76 \pm 0.17^{\mathrm{c}}$ & $2.38 \pm 0.82^{\mathrm{b}}$ & $5.15 \pm 0.16^{\mathrm{c}}$ & $2.65 \pm 0.97^{\mathrm{b}}$ & $1.31 \pm 0.01^{\mathrm{a}}$ \\
\hline Escherichia coli & $4.61 \pm 2.11^{\mathrm{bc}}$ & $4.34 \pm 1.78^{\mathrm{bc}}$ & $3.15 \pm 0.72^{\mathrm{ab}}$ & $2.32 \pm 0.83^{\mathrm{a}}$ & $5.70 \pm 0.31^{\mathrm{c}}$ & $3.10 \pm 0.43^{\mathrm{ab}}$ & $>10$ \\
\hline Bacillus subtilis & $8.29 \pm 0.98^{c}$ & $4.78 \pm 0.42^{\mathrm{b}}$ & $4.48 \pm 0.79^{\mathrm{b}}$ & $4.24 \pm 0.54^{\mathrm{b}}$ & $5.42 \pm 1.04^{\mathrm{b}}$ & $4.10 \pm 0.23^{\mathrm{b}}$ & $0.01 \pm 0^{\mathrm{a}}$ \\
\hline
\end{tabular}

Values are the mean of three replicates \pm SD. Means with different letters within a row were significantly different $(P<0.05)$. Benzylpenicillin was used as the positive control.

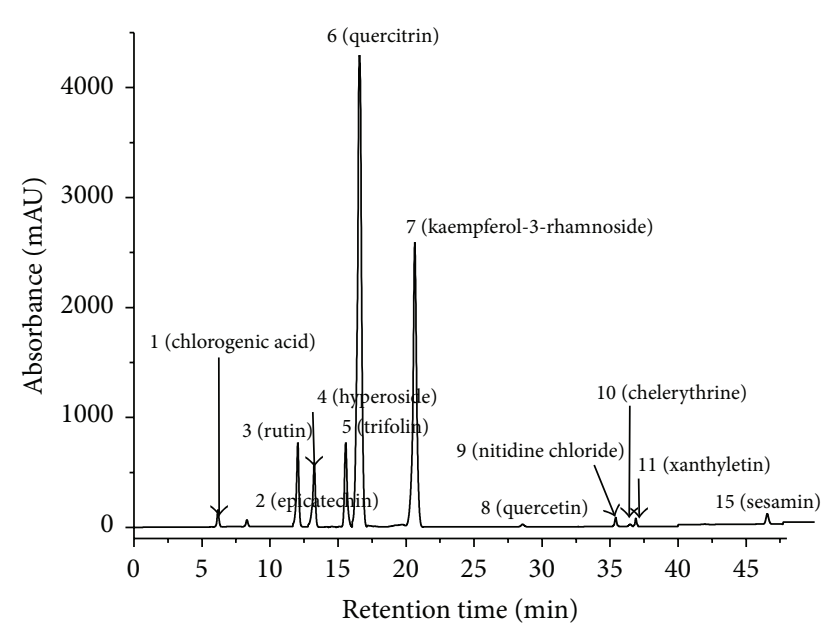

(a)

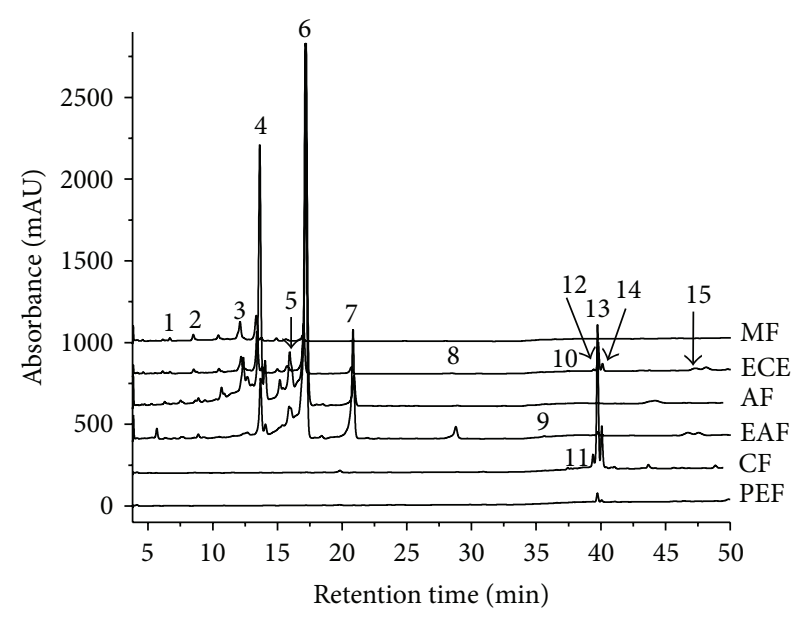

(b)

FIGURE 1: HPLC analysis of extracts and fractions from $Z$. bungeanum leaves. (a) Chromatography of the twelve standard compounds. (b) Chromatography of the ethanol extracts and their five fractions (ECE, PEF, CF, EAF, AF, and MF) monitored at $254 \mathrm{~nm}$ and identified by their retention time ( $\mathrm{min})$ : chlorogenic acid (6.62, peak 1), epicatechin (8.31, peak 2), rutin (12.12, peak 3$)$, hyperoside (13.61, peak 4), trifolin (15.73, peak 5), quercitrin (16.82, peak 6), Kaempferol-3-rhamnoside (20.61, peak 7), quercetin (28.32, peak 8), nitidine chloride (35.61, peak 9), chelerythrine (36.95, peak 10 ), xanthyletin (37.20, peak 11), and sesamin (46.44, peak 15). Peaks 9-11 were very weak.

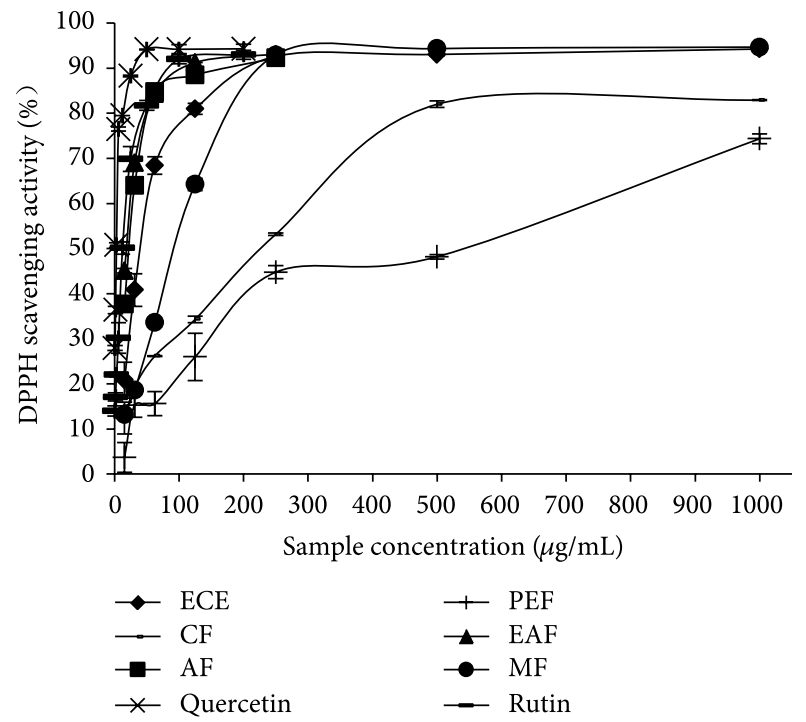

FIGURE 2: Scavenging effect on DPPH radical of extracts and fractions from $Z$. bungeanum leaves. Rutin and quercetin were used as the positive controls.

twelve compounds in $Z$. bungeanum leaves was established. Our current work has shown that the phytochemicals present in Z. bungeanum leaves have potent bioproperties and that the antioxidant properties are positively correlated with the total flavonoid and phenolic content. HPLC analysis indicated that the major phytochemicals (chlorogenic acid, epicatechin, rutin, hyperoside, trifolin, quercitrin, kaempferol-3rhamnoside, quercetin, sesamin, and nitidine chloride) were concentrated in the EAF and AF, which may be due to the enrichment effects during chromatographic fractionation. These bioactive phytochemicals might be responsible for their profound bioproperties. Furthermore, some lower polarity phytochemicals, such as kaempferol-3-rhamnoside, xanthyletin, sesamin, and other unknown compounds, might be responsible for the significant antifungal activity of $\mathrm{CF}$.

These results clearly demonstrated that the crude extracts and subfractions from the leaves of $Z$. bungeanum could be served as an accessible potential source for the production of functional food ingredients and medicinal exploration. This also could explain its frequent addition to the Chinese diet for promoting human health and for disease prevention. Further study is required to identify and quantify new bioactive 


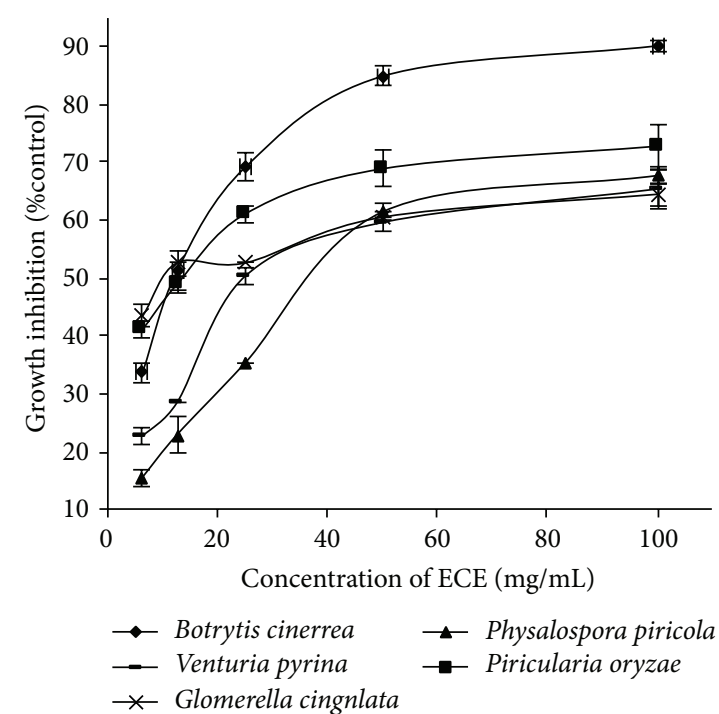

(a)

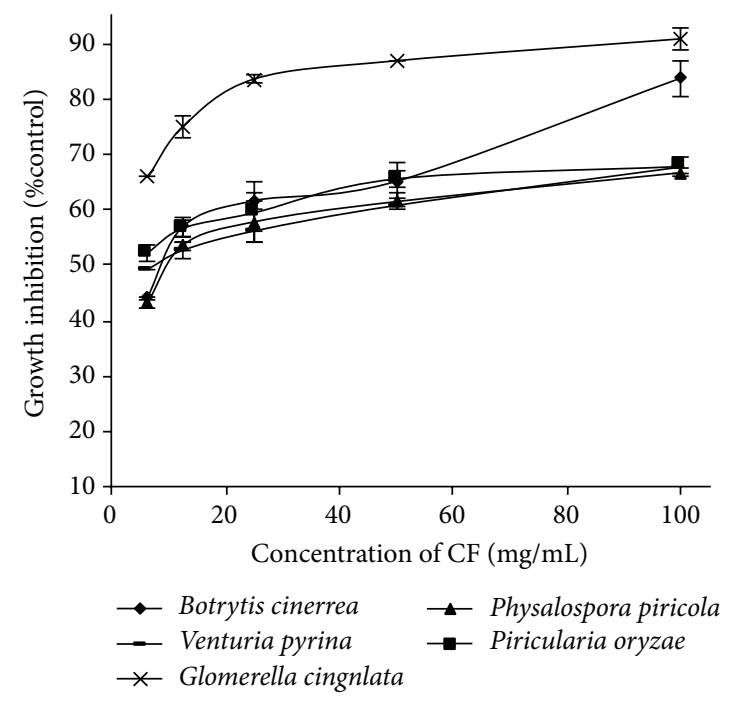

(c)
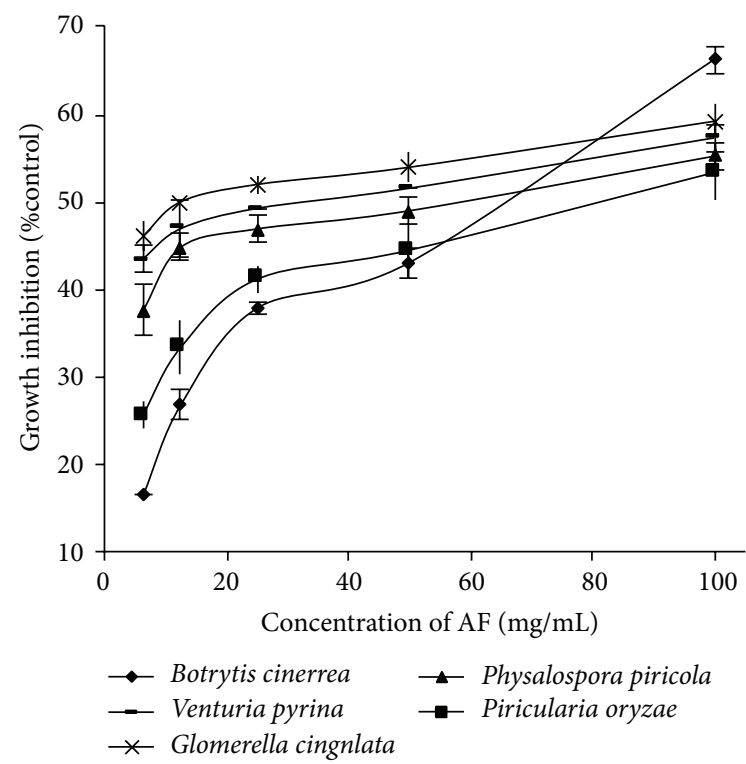

(e)

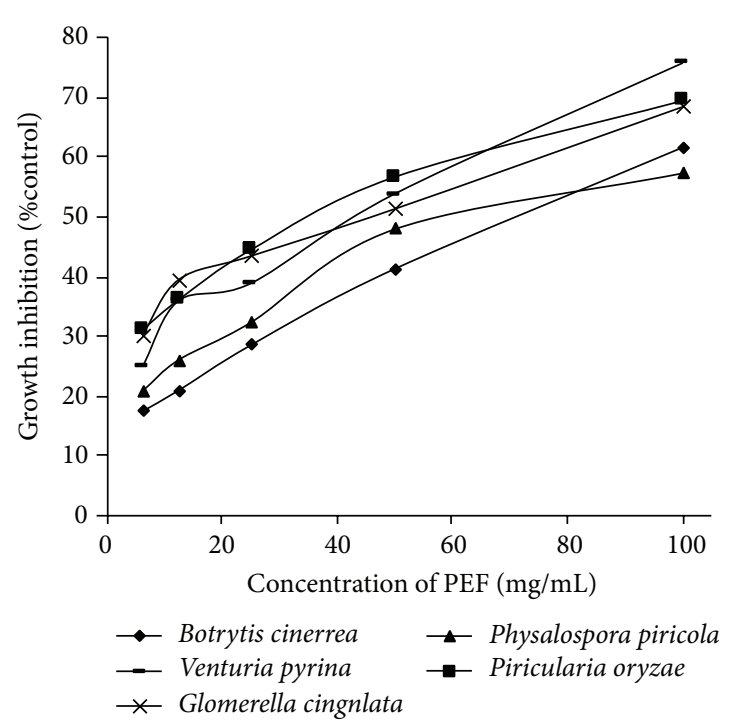

(b)

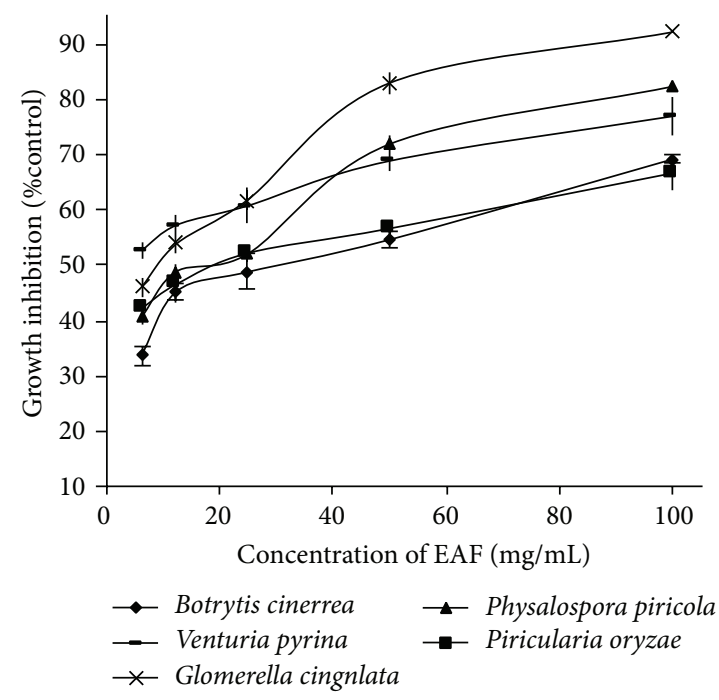

(d)
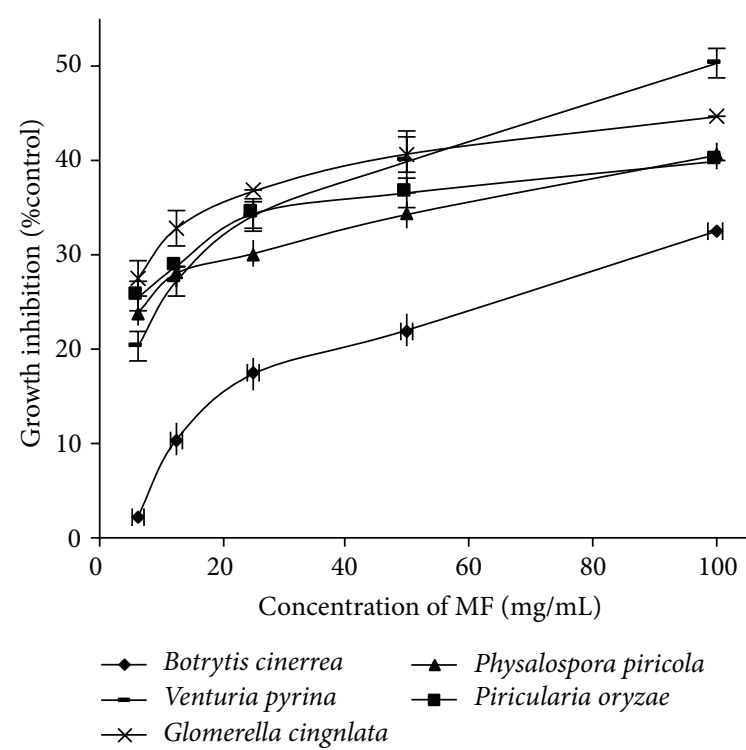

(f)

Figure 3: Continued. 


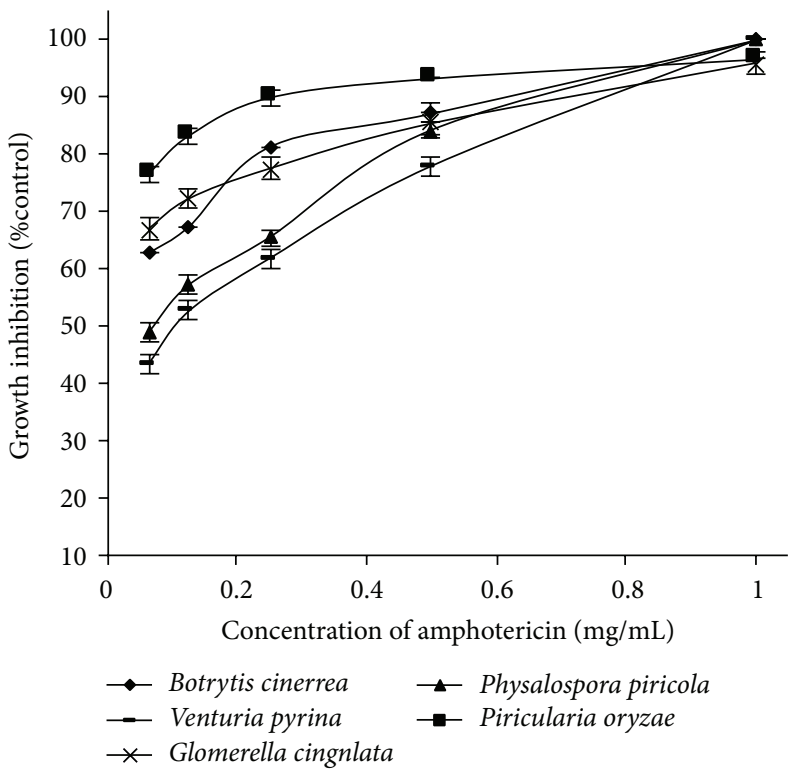

(g)

FIGURE 3: Inhibitory activity of extracts and fractions from Z. bungeanum leaves against 5 plant pathogenic fungi. Amphotericin was used as the positive control.

compounds from EAF, AF, and CF fractions; major bioactive compounds especially are worthwhile to be isolated and purified. Also, further cellular and in vivo studies of their biological activities are required.

\section{Conflict of Interests}

The authors declare that there is no conflict of interests regarding the publication of this paper.

\section{Acknowledgments}

The authors are grateful to the research fund from the Special Fund for Forestry Scientific Research in the Public Interest of China (201304811) and the Fundamental Research Funds for the Central Universities (ZD2013010).

\section{References}

[1] L.-C. Yang, R. Li, J. Tan, and Z. Jiang, "Polyphenolics composition of the leaves of Zanthoxylum bungeanum Maxim. grown in Hebei, China, and their radical scavenging activities," Journal of Agricultural and Food Chemistry, vol. 61, no. 8, pp. 1772-1778, 2013.

[2] X. G. Yang, "Aroma constituents and alkylamides of red and green huajiao (Zanthoxylum bungeanum and Zanthoxylum schinifolium)," Journal of Agricultural and Food Chemistry, vol. 56, no. 5, pp. 1689-1696, 2008.

[3] T. K. Lim, "Zanthoxylum simulans," in Edible Medicinal and Non-Medicinal Plants, pp. 904-911, Springer, 2012.

[4] Z. Q. Chang, F. Liu, S. L. Wang, T. Z. Zhao, and M. T. Wang, "Studies on the chemical constituents of Zanthoxylum simulans Hance," Acta Pharmaceutica Sinica, vol. 16, no. 5, pp. 394-396, 1981.
[5] J. A. Duke and E. S. Ayensu, Medicinal Plants of China, Reference Publications, Algonac, Mich, USA, 1985.

[6] H. C. Yeung, Handbook of Chinese Herbs and Formulas, Institute of Chinese Medicine, Los Angeles, Calif, USA, 1985.

[7] R. Bauer and P. G. Xiao, "Pericarpium Zanthoxyli Huajiao," in Chromatographic Fingerprint Analysis of Herbal Medicines, pp. 191-202, Springer, New York, NY, USA, 2011.

[8] X. L. Huang, N. Kakiuchi, Q. M. Che, S. Huang, M. Hattori, and T. Namba, "Effects of extracts of Zanthoxylum fruit and their constituents on spontaneous beating rate of myocardial cell sheets in culture," Phytotherapy Research, vol. 7, no. 1, pp. 41-48, 1993.

[9] C. Artaria, G. Maramaldi, A. Bonfigli, L. Rigano, and G. Appendino, "Lifting properties of the alkamide fraction from the fruit husks of Zanthoxylum bungeanum," International Journal of Cosmetic Science, vol. 33, no. 4, pp. 328-333, 2011.

[10] Y. Tezuka, S. Irikawa, T. Kaneko et al., "Screening of Chinese herbal drug extracts for inhibitory activity on nitric oxide production and identification of an active compound of Zanthoxylum bungeanum," Journal of Ethnopharmacology, vol. 77, no. 2-3, pp. 209-217, 2001.

[11] F. Yang, Y. Su, X. Li, Q. Zhang, and R. Sun, "Studies on the preparation of biodiesel from Zanthoxylum bungeanum Maxim seed oil," Journal of Agricultural and Food Chemistry, vol. 56, no. 17, pp. 7891-7896, 2008.

[12] Y. Gong, Y. Huang, L. Zhou et al., "Chemical composition and antifungal activity of the fruit oil of Zanthoxylum bungeanum maxim. (Rutaceae) from China," Journal of Essential Oil Research, vol. 21, no. 2, pp. 174-178, 2009.

[13] L. Xia, J. You, G. Li, Z. Sun, and Y. Suo, "Compositional and antioxidant activity analysis of Zanthoxylum bungeanum seed oil obtained by supercritical $\mathrm{CO}_{2}$ fluid extraction," Journal of the American Oil Chemists' Society, vol. 88, no. 1, pp. 23-32, 2011.

[14] Z. Y. Deng, B. Y. Sun, K. G. Kang et al., "Analysis of the main nutritional labeling in the tender bud of Zanthoxylum 
bungeanum," Journal of Northwest Forestry College, vol. 20, no. 1, pp. 179-180, 2005.

[15] H. D. Xu and J. H. Fan, "Macroporous adsorption resin purification of total flavonoids from the crude extract of Zanthoxylum bungeanum leaves and their reducing power and free radical scavenging activity," Food Science, vol. 31, no. 14, pp. 111-115, 2010.

[16] M. C. Cano-Campos, S. P. Díaz-Camacho, M. J. Uribe-Beltrán et al., "Bio-guided fractionation of the antimutagenic activity of methanolic extract from the fruit of Randia echinocarpa (Sessé et Mociño) against 1-nitropyrene," Food Research International, vol. 44, no. 9, pp. 3087-3093, 2011.

[17] D. M. Wang, Y. J. Zhang, S. S. Wang, and D. W. Li, "Antioxidant and antifungal activities of extracts and fractions from Anemone taipaiensis, China," Allelopathy Journal, vol. 32, no. 1, pp. 67-68, 2013.

[18] X. He, D. Liu, and H. L. Rui, "Sodium borohydride/chloranilbased assay for quantifying total flavonoids," Journal of Agricultural and Food Chemistry, vol. 56, no. 20, pp. 9337-9344, 2008.

[19] M. W. Zhang, R. F. Zhang, F. X. Zhang, and R. H. Liu, "Phenolic profiles and antioxidant activity of black rice bran of different commercially available varieties," Journal of Agricultural and Food Chemistry, vol. 58, no. 13, pp. 7580-7587, 2010.

[20] A. L. K. Faller, E. Fialho, and R. H. Liu, "Cellular antioxidant activity of Feijoada whole meal coupled with an in vitro digestion," Journal of Agricultural and Food Chemistry, vol. 60, no. 19, pp. 4826-4832, 2012.

[21] V. Singleton and J. A. Rossi, "Colorimetry of total phenolics with phosphomolybdic-phosphotungstic acid reagents," American Journal of Enology and Viticulture, vol. 16, no. 3, pp. 144-158, 1965.

[22] Y. Yao, W. Sang, M. Zhou, and G. Ren, "Phenolic composition and antioxidant activities of 11 celery cultivars," Journal of Food Science, vol. 75, no. 1, pp. C9-C13, 2010.

[23] X. P. Shi and Y. S. Zhang, "Determination of total alkaloid in Zanthoxylum bungeanum by acid dye colorimetry," Chinese Wild Plant Resources, vol. 27, no. 6, pp. 62-64, 2008.

[24] L. Xiu-Qin, J. Chao, S. Yan-Yan, Y. Min-Li, and C. Xiao-Gang, "Analysis of synthetic antioxidants and preservatives in edible vegetable oil by HPLC/TOF-MS," Food Chemistry, vol. 113, no. 2, pp. 692-700, 2009.

[25] M. Slavin and L. Yu, "A single extraction and HPLC procedure for simultaneous analysis of phytosterols, tocopherols and lutein in soybeans," Food Chemistry, vol. 135, no. 4, pp. 27892795, 2012.

[26] Y. Zhao, Z. Xie, Y. Niu, H. Shi, P. Chen, and L. Yu, "Chemical compositions, HPLC/MS fingerprinting profiles and radical scavenging properties of commercial Gynostemma pentaphyllum (Thunb.) Makino samples," Food Chemistry, vol. 134, no. 1, pp. 180-188, 2012.

[27] G. C. Yen and H. Y. Chen, "Antioxidant activity of various tea extracts in relation to their antimutagenicity, Journal of Agricultural and Food Chemistry, vol. 43, no. 1, pp. 27-32, 1995.

[28] B. Sultana, Z. Hussain, M. Asif, and A. Munir, "Investigation on the antioxidant activity of leaves, peels, stems, bark, and kernel of Mango (Mangifera indica L.)," Journal of Food Science, vol. 77, no. 8, pp. C849-C852, 2012.

[29] C. A. Rice-Evans, N. J. Miller, and G. Paganga, "Structureantioxidant activity relationships of flavonoids and phenolic acids," Free Radical Biology and Medicine, vol. 20, no. 7, pp. 933956, 1996.
[30] S. Tachakittirungrod, S. Okonogi, and S. Chowwanapoonpohn, "Study on antioxidant activity of certain plants in Thailand: mechanism of antioxidant action of guava leaf extract," Food Chemistry, vol. 103, no. 2, pp. 381-388, 2007.

[31] S. Gouveia and P. C. Castilho, "Helichrysum monizii lowe: phenolic composition and antioxidant potential," Phytochemical Analysis, vol. 23, no. 1, pp. 72-83, 2012.

[32] G. Sudha, M. Sangeetha Priya, R. B. Indhu Shree, and S. Vadivukkarasi, "Antioxidant activity of ripe and unripe pepino fruit (Solanum muricatum Aiton)," Journal of Food Science, vol. 77, no. 11, pp. C1131-C1135, 2012.

[33] I. F. F. Benzie and J. J. Strain, "The ferric reducing ability of plasma (FRAP) as a measure of "antioxidant power": the FRAP assay," Analytical Biochemistry, vol. 239, no. 1, pp. 70-76, 1996.

[34] D. J. de Rodríguez, D. Hernández-Castillo, R. RodríguezGarcía, and J. L. Angulo-Sánchez, "Antifungal activity in vitro of Aloe vera pulp and liquid fraction against plant pathogenic fungi," Industrial Crops and Products, vol. 21, no. 1, pp. 81-87, 2005.

[35] H. Ai, F. R. Wang, Y. Q. Xia, X. Chen, and C. Lei, "Antioxidant, antifungal and antiviral activities of chitosan from the larvae of housefly, Musca domestica L.," Food Chemistry, vol. 132, no. 1, pp. 493-498, 2012.

[36] F. Hsu, P. Chen, H. Chang, and S. Chang, "Effects of alkyl chain length of gallates on their antifungal property and potency as an environmentally benign preservative against wood-decay fungi," International Biodeterioration and Biodegradation, vol. 63, no. 5, pp. 543-547, 2009.

[37] J. Tian, X. Q. Ban, H. Zeng, J. He, B. Huang, and Y. Wang, "Chemical composition and antifungal activity of essential oil from Cicuta virosa L. var. latisecta Celak," International Journal of Food Microbiology, vol. 145, no. 2-3, pp. 464-470, 2011.

[38] J. W. Gong, B. F. Hu, L. L. Yan et al., "Comparative study on bacteriostasis of extracts from Zanthoxylum bungeanum," Guangdong Agricultural Science, vol. 38, no. 24, pp. 57-58, 2011.

[39] N. G. Baydar, G. Özkan, and O. Sağdiç, "Total phenolic contents and antibacterial activities of grape (Vitis vinifera L.) extracts," Food Control, vol. 15, no. 5, pp. 335-339, 2004.

[40] F. Bourgaud, A. Gravot, S. Milesi, and E. Gontier, "Production of plant secondary metabolites: a historical perspective," Plant Science, vol. 161, no. 5, pp. 839-851, 2001.

[41] I. H.-. Chen, S. Wu, Y. Leu, I. Tsai, and T. Wu, "Alkaloids from root bark of Zanthoxylum simulans," Phytochemistry, vol. 42, no. 1, pp. 217-219, 1996.

[42] L. J. Ren and F. Z. Xie, "Alkaloids from the root of Zanthoxylum bungeaum Maxim," Acta Pharmaceutica Sinica, vol. 16, no. 9, pp. 672-677, 1981.

[43] P. Jiang, F. Burczynski, C. Campbell, G. Pierce, J. A. Austria, and C. J. Briggs, "Rutin and flavonoid contents in three buckwheat species Fagopyrum esculentum, F. tataricum, and F. homotropicum and their protective effects against lipid peroxidation," Food Research International, vol. 40, no. 3, pp. 356-364, 2007.

[44] A. P. M. Bernardi, J. de Matos Nunes, M. K. Marchioro, L. M. G. Rosa, G. L. von Poser, and S. B. Rech, "Phenolic compounds profiles during ex vitro acclimatization of micropropagated Hypericum polyanthemum," Plant Physiology and Biochemistry, vol. 46, no. 7, pp. 694-700, 2008.

[45] S. Okonogi, C. Duangrat, S. Anuchpreeda, S. Tachakittirungrod, and S. Chowwanapoonpohn, "Comparison of antioxidant capacities and cytotoxicities of certain fruit peels," Food Chemistry, vol. 103, no. 3, pp. 839-846, 2007. 
[46] R. L. Prior, X. Wu, and K. Schaich, "Standardized methods for the determination of antioxidant capacity and phenolics in foods and dietary supplements," Journal of Agricultural and Food Chemistry, vol. 53, no. 10, pp. 4290-4302, 2005.

[47] D. Huang, O. U. Boxin, and R. L. Prior, "The chemistry behind antioxidant capacity assays," Journal of Agricultural and Food Chemistry, vol. 53, no. 6, pp. 1841-1856, 2005.

[48] A. Sokół-Łętowska, A. Z. Kucharska, K. Wińska et al., "Composition and antioxidant activity of red fruit liqueurs," Food Chemistry, vol. 157, pp. 533-539, 2014.

[49] A. S. Buru, M. R. Pichika, V. Neela et al., "In vitro antibacterial effects of Cinnamomum extracts on common bacteria found in wound infections with emphasis on methicillin-resistant Staphylococcus aureus," Journal of Ethnopharmacology, vol. 153, no. 3, pp. 587-595, 2014. 

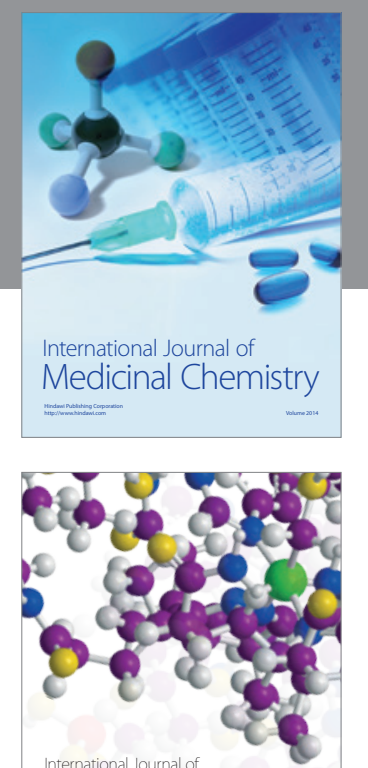

\section{Carbohydrate} Chemistry

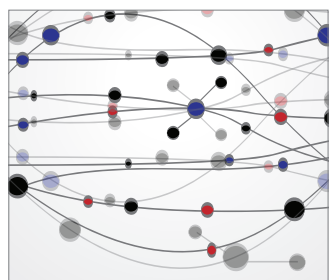

The Scientific World Journal
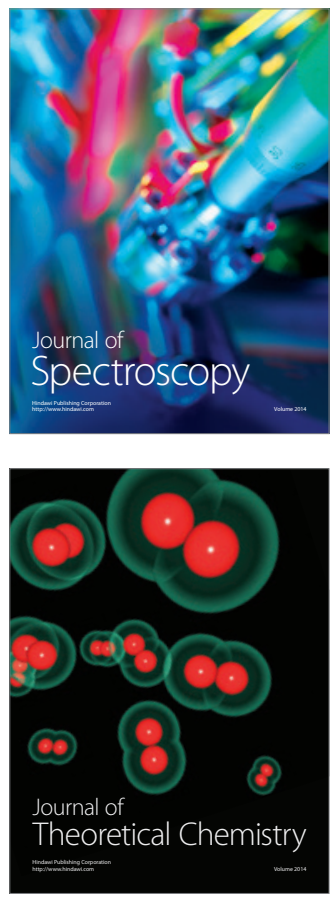
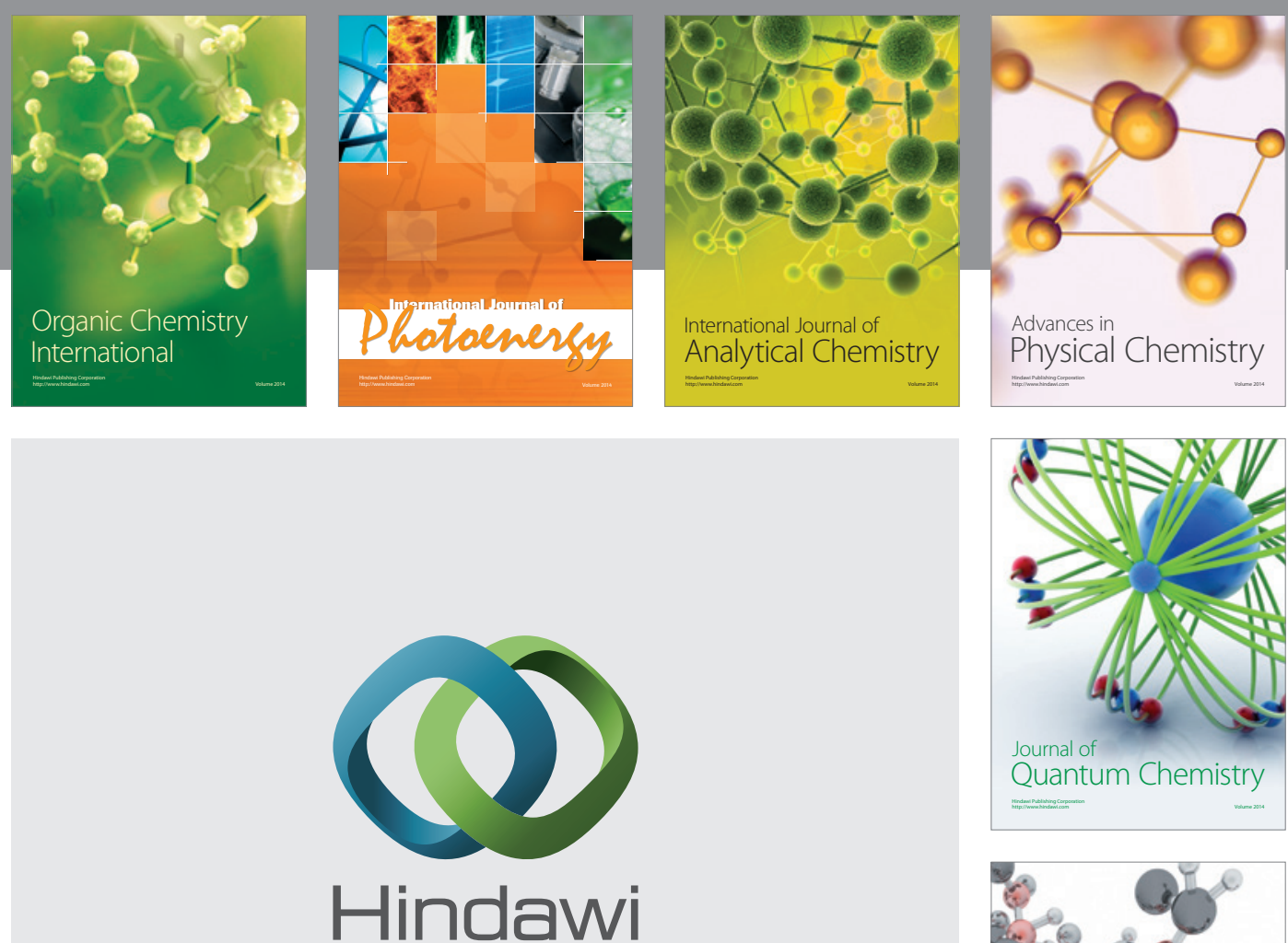

Submit your manuscripts at

http://www.hindawi.com

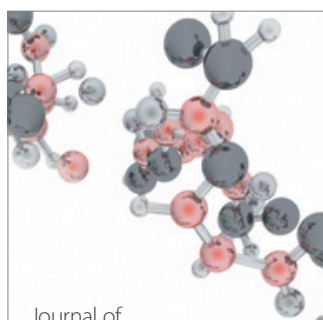

Analytical Methods

in Chemistry

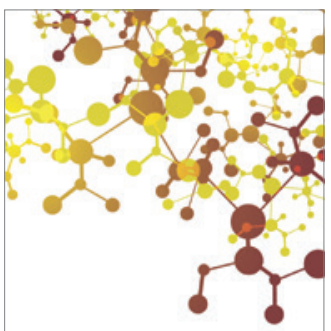

Journal of

Applied Chemistry

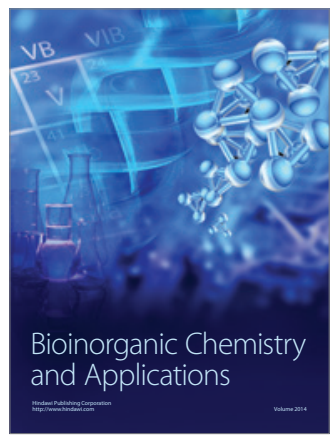

Inorganic Chemistry
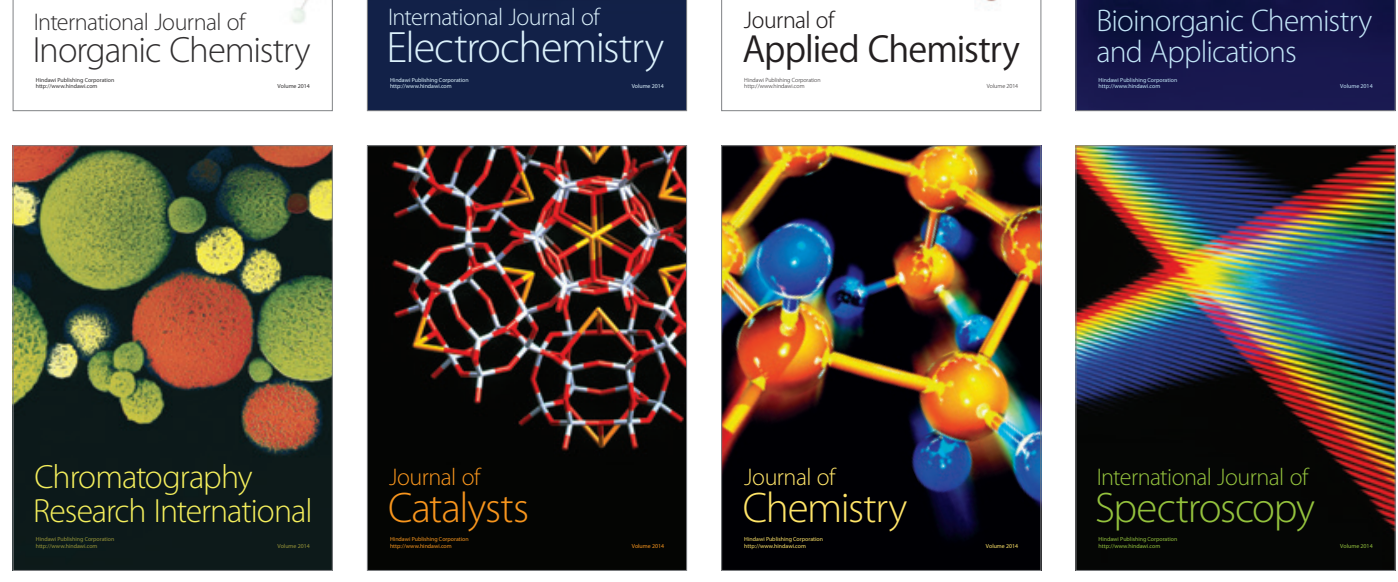